\title{
Successful Treatment of Advanced Primary Cutaneous Apocrine Carcinoma on the Scrotum with Systemic Chemotherapy and Radiotherapy Followed by Denosumab
}

\author{
Sadanori Furudate Taku Fujimura Akira Tsukada Yota Sato \\ Takanori Hidaka Kayo Tanita Yumi Kambayashi Takahiro Haga \\ Akira Hashimoto Setsuya Aiba \\ Department of Dermatology, Tohoku University Graduate School of Medicine, \\ Sendai, Japan
}

\section{Keywords}

Primary cutaneous apocrine carcinoma $\cdot$ RANKL $\cdot$ Chemoradiotherapy · Denosumab · Tumor microenvironment

\begin{abstract}
Primary cutaneous apocrine carcinoma (PCAC) is a rare and highly aggressive cutaneous adnexal type of tumor that has a high metastasis rate and a poor prognosis. Although there are several case reports describing the successful treatment of PCAC with chemoradiotherapy or molecular targeting therapy, no standard therapy for the treatment of advanced PCAC has been established yet. Since receptor activator of nuclear factor kappa-B ligand (RANKL) is expressed in cancers of apocrine origin, leading to immunosuppression at the tumor site, we hypothesized that targeting RANKL with denosumab might be useful for the treatment of PCAC. In this report, we describe a case with advanced PCAC on the scrotum successfully treated with systemic chemotherapy using carboplatin and paclitaxel, and radiotherapy followed by denosumab.




\section{Introduction}

Primary cutaneous apocrine carcinoma (PCAC) is a rare and highly aggressive cutaneous adenocarcinoma that generally occurs in the axilla [1-4]. Although there are several case reports describing the successful treatment of PCAC with chemoradiotherapy or molecular targeting therapy, no standard therapy for the treatment of advanced PCAC has been established yet. In this report, we describe a case with advanced PCAC on the scrotum successfully treated with systemic chemotherapy using carboplatin and paclitaxel, and radiotherapy followed by denosumab.

\section{Case Report}

A 77-year-old man presented with a 3-year history of erosive erythema with nodules on the scrotum. At his initial visit, physical examination revealed extensive erosive erythema with a red, easy-to-bleed nodule on the scrotum (Fig. 1a). Skin biopsy from the nodule revealed tumor cells mainly proliferating in the dermis, forming solid pattern nests and upward pagetoid epidermal migration (Fig. 1b). Immunohistochemical staining revealed that these tumor cells were positive for CK7, gross cystic disease fluid protein (GCDFP)-15, receptor activator of nuclear factor kappa-B ligand (RANKL) (Fig. 1c), and MMP7 and negative for CK20 and CDX2. From the above findings, we diagnosed this case as PCAC.

There was no significant enlargement of the bilateral inguinal lymph nodes at the initial visit. We screened for possible internal malignancy with positron emission tomography (PET)-CT, and found no evidence of metastasis. Since magnetic resonance imaging (MRI) revealed that the tumor mass developed adjacent to the urethra (Fig. 2a), we consulted an urologist and found that the tumor infiltrated into the urethra, corpus cavernosum of the penis, and testis. During the consultation, a significant enlargement of the bilateral inguinal lymph nodes was revealed. Since the patient refused radical excision of the tumor, we administered carboplatin (AUC $\times[\mathrm{Ccr}+25] \mathrm{mg}$ ) and paclitaxel $\left(200 \mathrm{mg} / \mathrm{m}^{2}\right)$ intravenously 3 times, and subcutaneous denosumab $(60 \mathrm{mg}$ ) once every 6 months. In addition, radiotherapy was performed on the scrotum and bilateral inguinal region at a total dose of $58 \mathrm{~Gy}$.

Two months after administrating this combination therapy, all primary tumors had disappeared histologically (primary site) (Fig. 2b) and on the MRI (Fig. 2c). A follow-up CT scan revealed a diminished swelling of the bilateral inguinal lymph nodes. Half a year after the remission of the primary and lymph node metastatis, the apocrine carcinoma was still under remission.

\section{Discussion}

In this report, we describe a case with advanced PCAC on the scrotum successfully treated with systemic chemotherapy using carboplatin and paclitaxel, and radiotherapy followed by denosumab. PCAC is a rare cutaneous adnexal tumor that has a high metastasis rate and a poor prognosis [1-3]. Since there is no standardized chemotherapy for PCAC, the treatment of PCAC is sometimes exploratory. For example, human epidermal growth factor receptor 2 (HER-2) signal inhibitors, such as trastuzumab and lapatinib, which are used as a standard therapy for HER-2-overexpressing cancer [5], are effective even for metastatic 
Furudate et al:: Successful Treatment of Advanced PCAC on the Scrotum with Systemic Chemotherapy and Radiotherapy Followed by Denosumab

HER-2-overexpressing PCAC $[1,2]$. Another report also suggested that the chemotherapeutic regimen for breast cancer is effective for the treatment of PCAC [3].

Since PCAC is histologically similar to the apocrine subtype of breast cancer [6], the biological behavior and reactivity of PCAC to chemotherapy might resemble those of breast cancer. Indeed, PCAC tends to express apocrine-derived cell surface markers such as GCDFP15 and HER-2 [1-4]. In addition, as we have previously reported, extramammary Paget's disease, another apocine-derived skin tumor, expresses RANKL, leading to a sustained immunosuppressive tumor microenvironment through tumor-associated macrophages, Langerhans cells, and regulatory T cells [7-10]. These reports suggest that RANKL plays a critical role in maintaining the tumor microenvironment of skin cancer of apocrine origin and that targeting RANKL with anti-RANKL antibody, i.e. denosumab, might be useful for the therapeutic elimination of the primary invasive tumor and metastatic disease.

Based on the above findings, we administered denosumab after chemoradiotherapy. Since RANKL, a key paracrine effector of progesterone signaling, and its receptor RANK contribute to mammary tumorigenesis and tumor proliferation $[11,12]$, denosumab might work not only as an immunomodulatory factor but also as a direct tumor suppressor for apocrine carcinomas. Indeed, an adjuvant effect of denosumab was observed in the present case. Since this report presents only a single case, subsequent cases may provide greater insight into the anti-tumor effects of denosumab in the treatment of RANKL-expressing apocrine tumors.

\section{Disclosure Statement}

The authors have no conflicts of interest to declare.

\section{Statement of Ethics}

The patient gave written informed consent.

\section{References}

1 Hidaka T, Fujimura T, Watabe A, Hashimoto A, Haga T, Onami K, Mizuashi M, Aiba S: Successful treatment of HER-2-positive metastatic apocrine carcinoma of the skin with lapatinib and capecitabine. Acta Derm Venereol 2012;92:654-655.

-2 Otsuka M, Yamasaki O, Kaji T, Shien T, Iwatsuki K: Metastatic cutaneous apocrine adenocarcinoma treated with a combination of pertuzumab-based targeted therapy and taxane chemotherapy: a case report. JAMA Dermatol 2016;152:111-113.

-3 Fujisawa Y, Fujimoto M: Metastatic cutaneous apocrine carcinoma of the axilla successfully treated using systemic chemotherapy with i.v. epirubicin and cyclophosphamide followed by oral fluorinated pyrimidine. J Dermatol 2014;41:280-282.

4 Kambayashi Y, Fujimura T, Furudate S, Asano M, Kakizaki A, Aiba S: The possible interaction between receptor activator of nuclear factor kappa-B ligand (RANKL) expressed by extramammary Paget cells and its ligand on dermal macrophages. J Invest Dermatol 2015;135:2547-2550.

-5 Fujimura T, Kambayashi Y, Furudate S, Asano M, Kakizaki A, Aiba S: Receptor activator of nuclear factor kappa-B ligand (RANKL) promotes the production of CCL17 from RANK+ M2 macrophages. J Invest Dermatol 2015;135:2884-2887.

-6 Fujimura T, Kambayashi Y, Furudate S, Kambayashi Y, Asano M, Watabe A, Aiba S: Receptor activator of nuclear factor kappa-B ligand (RANKL)/RANK signaling promotes cancer-related inflammation through M2 macrophages. Exp Dermatol 2016;25:397-399. 


\section{Case Reports in Oncology}

\begin{tabular}{|c|c|}
\hline Case Rep Oncol 2017;10: & \\
\hline DOI: 10.1159/000455091 & $\begin{array}{l}\text { (c) } 2017 \text { The Author(s). Published by S. Karger AG, Basel } \\
\text { www.karger.com/cro }\end{array}$ \\
\hline
\end{tabular}

Furudate et al.: Successful Treatment of Advanced PCAC on the Scrotum with Systemic Chemotherapy and Radiotherapy Followed by Denosumab

7 Fujimura T, Kambayashi Y, Furudate S, Kakizaki A, Hidaka T, Aiba S: Possible mechanisms of the crosstalk between Langerhans cells and regulatory T cells in extramammary Paget disease by receptor activator of nuclear factor kappa B (RANK) ligand/RANK pathways. Brit J Dermatol 2016, DOI: $10.1111 /$ bjd.14864.

-8 Cardoso JC, Calonje E: Malignant sweat gland tumours: an update. Histopathology 2015;67:589-606.

9 Aebi S, Davidson T, Gruber G, Castiglione M: Primary breast cancer: ESMO Clinical Practice Guidelines for diagnosis, treatment and follow-up. Ann Oncol 2010;21(suppl 5):v9-v14.

-10 Press MF, Finn RS, Cameron D, Di Leo A, Geyer CE, Villalobos IE, Santiago A, Guzman R, Gasparyan A, Ma Y, Danenberg K, Martin AM, Williams L, Oliva C, Stein S, Gagnon R, Arbushites M, Koehler MT: HER-2 gene amplification, HER-2 and epidermal growth factor receptor mRNA and protein expression, and lapatinib efficacy in women with metastatic breast cancer. Clin Cancer Res 2008;14:7861-7870.

-11 Nolan E, Vaillant F, Branstetter D, Pal B, Giner G, Whitehead L, Lok SW, Mann GB; Kathleen Cuningham Foundation Consortium for Research into Familial Breast Cancer (kConFab), Rohrbach K, Huang LY, Soriano R, Smyth GK, Dougall WC, Visvader JE, Lindeman GJ: RANK ligand as a potential target for breast cancer prevention in BRCA1-mutation carriers. Nat Med 2016;22:933-939.

-12 Gonzalez-Suarez E, Jacob AP, Jones J, Jones J, Miller R, Roudier-Meyer MP, Erwert R, Pinkas J, Branstetter D, Dougall WC: RANK ligand mediates progestin-induced mammary epithelial proliferation and carcinogenesis. Nature 2010;468:103-107.
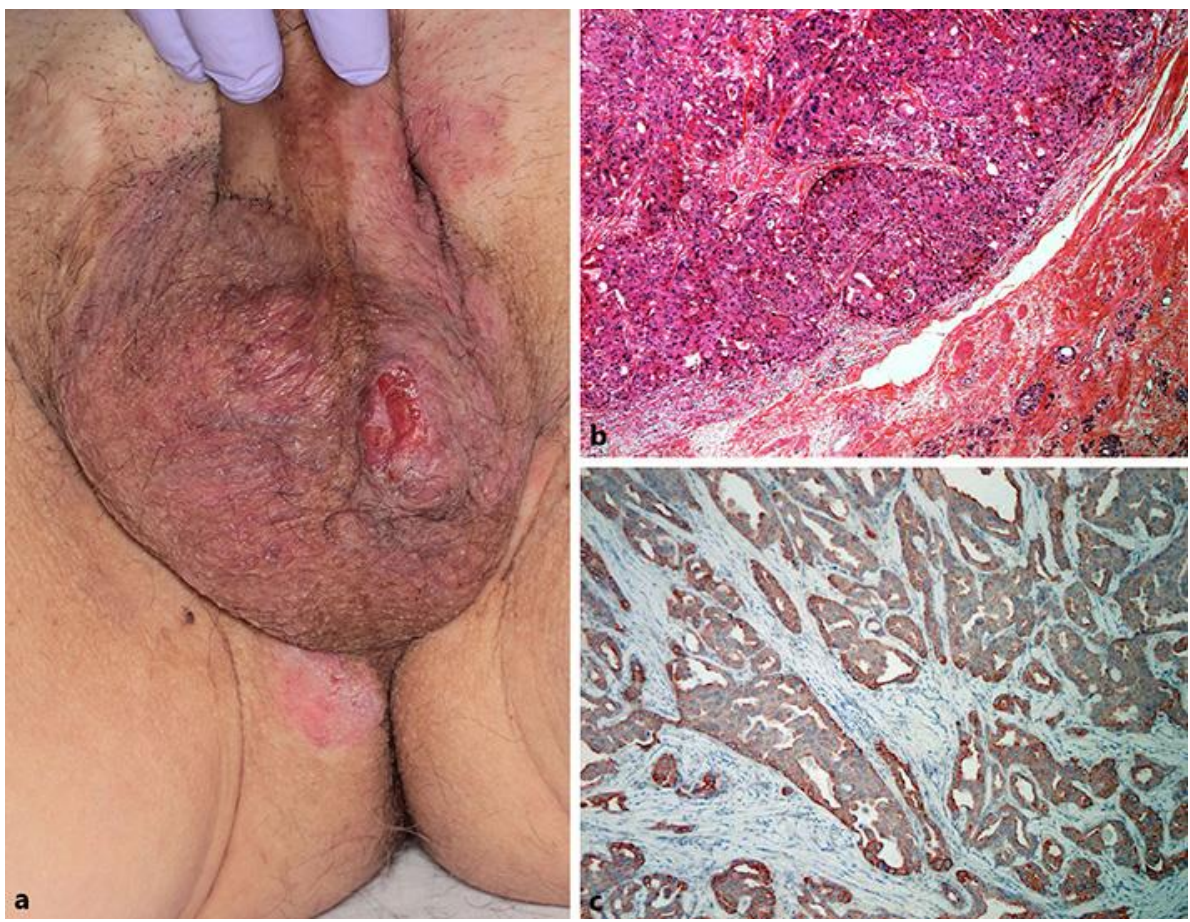

Fig. 1. An extensive erosive erythema with a red, easy-to-bleed nodule on the scrotum (a). Atypical cells mainly proliferated in the dermis forming solid pattern nests (b). Paraffin-embedded tissue samples from the right shoulder were deparaffinized and stained with anti-RANKL antibody (c). 


\section{Case Reports in Oncology}

\begin{tabular}{|c|c|}
\hline Case Rep Oncol 2017;10 & \\
\hline DOI: $10.1159 / 000455091$ & $\begin{array}{l}\text { (c) } 2017 \text { The Author(s). Published by S. Karger AG, Basel } \\
\text { www.karger.com/cro }\end{array}$ \\
\hline
\end{tabular}

Furudate et al: Successful Treatment of Advanced PCAC on the Scrotum with Systemic Chemotherapy and Radiotherapy Followed by Denosumab
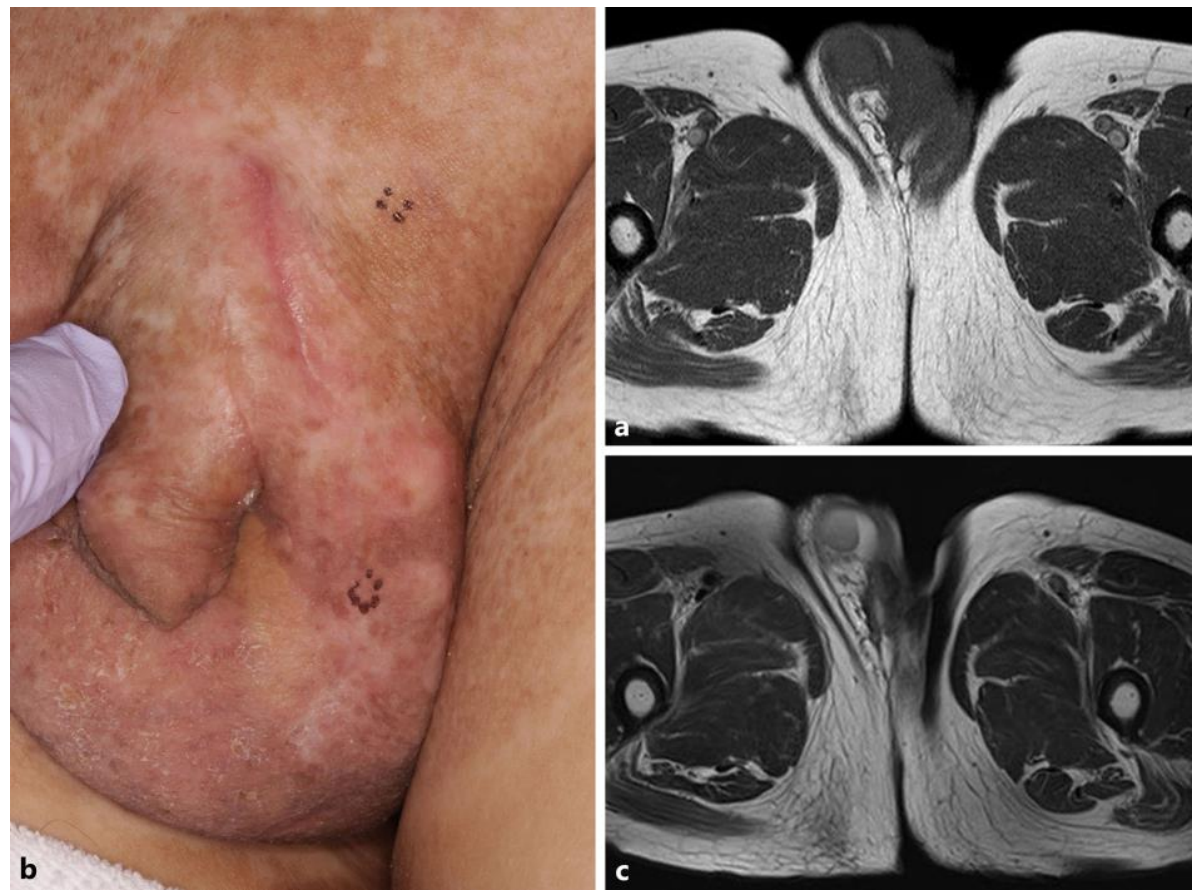

Fig. 2. T1-weighted MRI before the treatment (a). Physical examination revealed that all primary tumors had disappeared (b). T1-weighted MRI after the treatment (c). 